\title{
Unusual presentation of anterior sacral meningocele- a rare case report
}

\author{
Rajesh baghel ${ }^{1}$, Akshara Gupta ${ }^{2}$, Sanjay chandel ${ }^{3}$ \\ 1\&2. Department of radiodiagnosis, GR medical college, Gwalior MP, India \\ ${ }^{3 .}$ Department of raditherapy, GR medical college, Gwalior MP, India
}

\begin{abstract}
A 14 year old girl presented as abdominal distension, on Ultrasonography it appear like Ovarian mass, Computed Tomography of abdomen and magnetic resonance imaging suggest Anterior sacral meningocele, which is very rare case, only less than 150 cases reported in literature.

Keywords: anterior sacral meningocele.
\end{abstract}

\section{Introduction}

Anterior sacral meningocele usually presents with a pelvic mass causing symptoms related to compression of nearby organs, neurological symptoms or its complications in the form of meningitis. Here we present a case of 14 year old girl with abdominal distension that turned out to be anterior sacral meningocele on radiologic evaluation and confirmed per-operatively. The peculiarity of our case is that the patient didn't have urologic, gynaecologic, neurologic and gastrointestinal symptoms except for abdominal distension.

\section{Case report}

14 yr old girl came to our department from gynaecolgy department with the presumed diagnosis of ovarian mass. The patient's complaint was progressive abdominal distension since birth. Abdominal USG revealed a cystic mass occupying whole of the abdomen, morphologically normal uterus, adnexa and nonvisualization of left kidney. Abdominal CT revealed cystic mass with no solid component, defects in anterior aspect of L4, L5 and sacral vertebrae. The mass is seen communicating with subarachnoid space through this defect. Uterus and adnexa were seen displaced to the right by the mass. Also noted incidentally is the unilateral absence of left kidney. The patient then underwent MRI which showed cystic fluid following CSF signal intensity and no nerve roots were seen entering into the mass. A diagnosis of anterior sacral meningocele was made. Peroperatively the defect was approached posteriorly by laminectomy of L4 \& L5 vertebrae, stalk was clamped and dural defect closed with patch of fascia.

\section{Discussion}

anterior sacral menigocele, a rare congenital anomaly (1), protrudes through a rent in the anterior part of vertebrae, but sometimes pedicle defect also noted and presents as a presacral pelvic mass It is more common in females than males ratio 4:1, it has been proposed that it is an autosomal dominant (2).it is recognised within the heritable currarino triad, consisting of congenital anal stenosis, scimitar sacrum and presacral mass(meningocele)(3). It has also been associated with marfan's syndrome and neurofibromatosis; however most of cases are sporadic. The usual age of presentation in females in second and third decade, though it can present in the first decade in males.

Localized symptoms of anterior sacral meningocele are present in two third of all cases (4). The symptoms are due to pressure from ASM on sacral nerve roots, genitalia, rectum and bladder.The patient usually presents with abdominal distension, obstructive symptoms in form of constipation, urinary incontinence, low backache, headache and meningitis. However our patient didn't have any symptoms other than abdominal distension. From a gynecologist perspective, on palpation ASM can mimic an ovarian cyst or other adnexal cystic lesion, but the ASM will be located more posteriorly (5). With regards to radiological diagnosis, there is the general acceptance that a scimitar shaped sacrum (a concave defect in one side of the sacrum) is often diagnostic on plain radiography (plain X-ray of the pelvis). (6) CT scan and MRI are the investigation of choice (7). The cord and the caudaequina have been reported to be usually normal (8).Hydronephrosis usually expected with such a huge retroperitoneal cyst is not seen in our case, a new finding in the literature. Also noted is the incidental absence of left kidney, which as of date has not been associated with anterior sacral meningocele. This case signifies anterior sacral menigocele should be in the differential diagnosis of a cystic abdominal mass regardless of the patient's neurologic, urologic and gynaecologic complaints.

\section{FIGURES:}

Legends: I picture showing MRI Scan of abdomen

Legends II picture showing CT scan of abdomen 

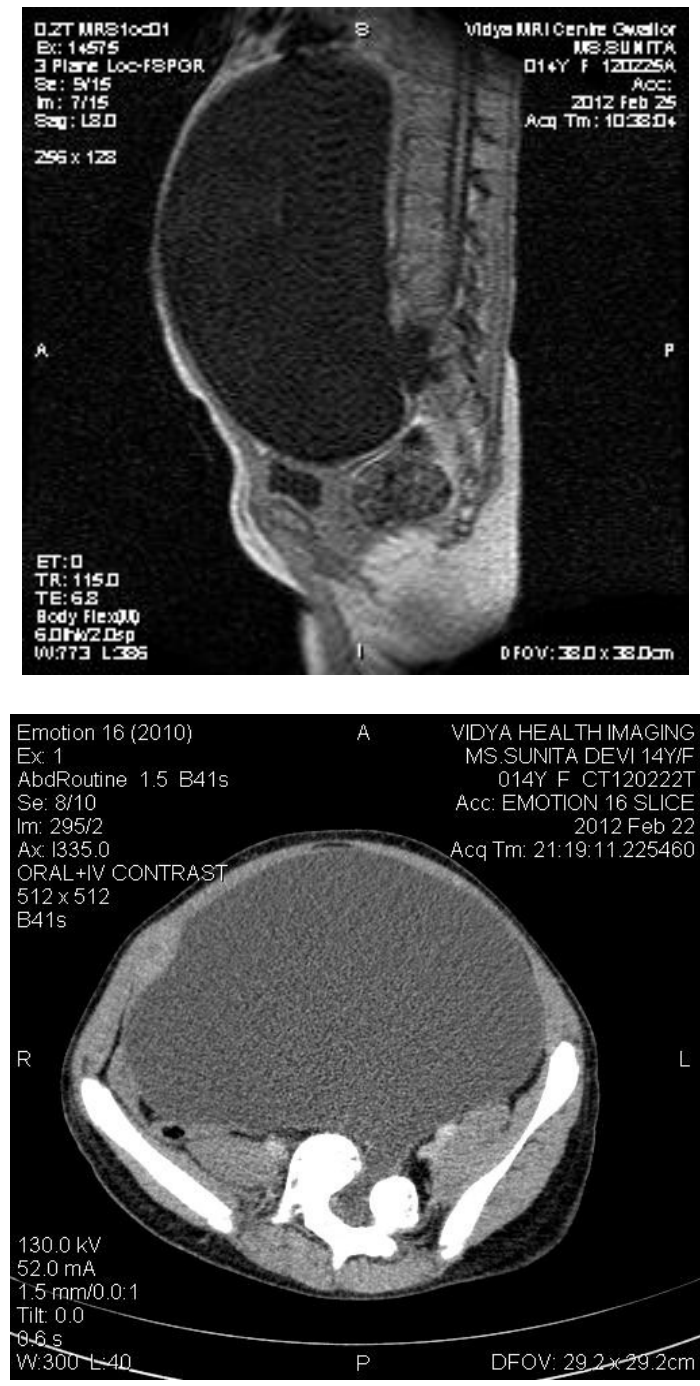

\section{Conclusion:}

In our case on the basis of clinical and preliminary ultrasound examination provisional diagnosis was cystic ovarian mass, but CT and MRI suggest that it is case of anterior meningocele so we conclude that only ultrasonographic finding is not sufficient for confirmatory diagnosis of ASM.

\section{References}

[1]. Bryant $\mathrm{T}$, Case of deficiency of the anterior part of the sacrum with a thecal sac in the pelvis, similar to the tumour of spina bifida. Lancet1837; 1:258-360.

[2]. Yates VD, Wilroy RS, Whitington GL, Simmons JC. Anterior sacral defects: an autosomal dominantly inherited condition. J pediatr 1983; 102:239-242.

[3]. walton M, bass J, soucy P. tethered cord with anorectalmalformation,sacral anomalies and presacral masses: an under recognised association. Eur j paediatric surg 1995; 5(1):59-62

[4]. Lynch S, Wang Y, Strachan T, Burn J, Lindsay S. Autosomal dominant sacral agenesis: Currarino syndrome. J Med Genet 2000; 37:561-566.

[5]. Gardner PA, Albright AL. "Like mother, like son" hereditary anterior sacral meningocele Case.

[6]. Walton M, Bass J, Soucy P. Tettered cord with anorectal malformation, sacral anomalies and presacral masses; An under recognised association. Eur J PaediatrSurg 1995; 5:59-62 report and review of literature. J Neurosurg 2006; 104 (2suupl): 138-142.

[7]. Fitzpatrick M O, Taylor W A S. Anterior sacral meningocele associated with a rectal fistula. Case report and review of the literature.J Neurosurg (Spine), 1999; 91: 124-127.

[8]. Jaffee R, Anterior sacral meningocele, report of a case. Obstet Gynecol 1966; 28: $684-686$. 